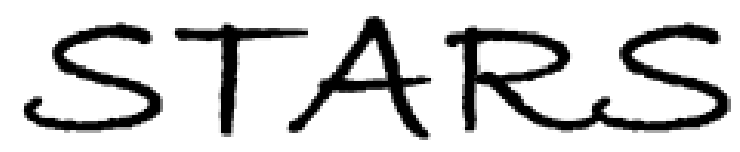

University of Central Florida

STARS

Faculty Bibliography 2000s

Faculty Bibliography

$1-1-2005$

\title{
$p$ type doping of zinc oxide by arsenic ion implantation
}

G. Braunstein

University of Central Florida

A. Muraviev

University of Central Florida

H. Saxena

University of Central Florida

N. Dhere

University of Central Florida

V. Richter

See next page for additional authors

Find similar works at: https://stars.library.ucf.edu/facultybib2000

University of Central Florida Libraries http://library.ucf.edu

This Article is brought to you for free and open access by the Faculty Bibliography at STARS. It has been accepted for inclusion in Faculty Bibliography 2000s by an authorized administrator of STARS. For more information, please contactSTARS@ucf.edu.

\section{Recommended Citation}

Braunstein, G.; Muraviev, A.; Saxena, H.; Dhere, N.; Richter, V.; and Kalish, R., "p type doping of zinc oxide by arsenic ion implantation" (2005). Faculty Bibliography 2000s. 5010.

https://stars.library.ucf.edu/facultybib2000/5010

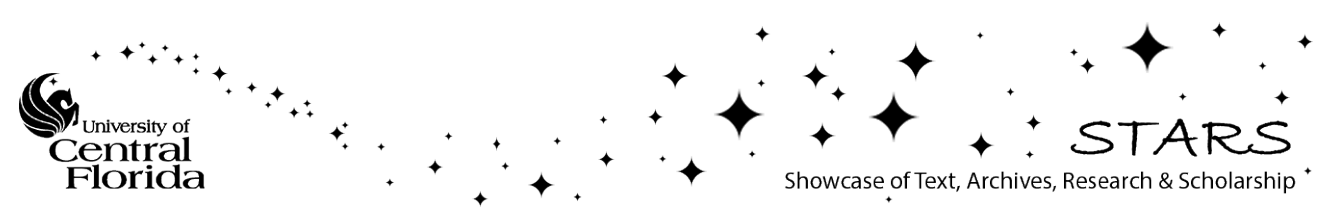


Authors

G. Braunstein, A. Muraviev, H. Saxena, N. Dhere, V. Richter, and R. Kalish 


\title{
$p$ type doping of zinc oxide by arsenic ion implantation
}

\author{
G. Braunstein, a) A. Muraviev, and H. Saxena \\ Department of Physics, University of Central Florida, Orlando, Florida 32816 \\ N. Dhere \\ Florida Solar Energy Center, University of Central Florida, Cocoa, Florida 32922 \\ V. Richter and R. Kalish \\ Solid State Institute and Department of Physics, Technion, Haifa 32000, Israel
}

(Received 29 June 2005; accepted 13 September 2005; published online 31 October 2005)

\begin{abstract}
$p$ type doping of polycrystalline $\mathrm{ZnO}$ thin films, by implantation of arsenic ions, is demonstrated. The approach consisted of carrying out the implantations at liquid-nitrogen temperature $\left(\sim-196{ }^{\circ} \mathrm{C}\right)$, followed by a rapid in situ heating of the sample, at $560{ }^{\circ} \mathrm{C}$ for $10 \mathrm{~min}$, and ex situ annealing at $900{ }^{\circ} \mathrm{C}$ for $45 \mathrm{~min}$ in flowing oxygen. $p$ type conductivity with a hole concentration of $2.5 \times 10^{13} \mathrm{~cm}^{-2}$ was obtained using this approach, following implantation of $150 \mathrm{keV}$ $5 \times 10^{14} \mathrm{As} / \mathrm{cm}^{2}$. A conventional room-temperature implantation of $1 \times 10^{15} \mathrm{As} / \mathrm{cm}^{2}$, followed by the same ex situ annealing, resulted in $n$ type conductivity with a carrier concentration of $1.7 \times 10^{12} \mathrm{~cm}^{-2}$. () 2005 American Institute of Physics. [DOI: 10.1063/1.2128064]
\end{abstract}

A significant amount of research activity is directed nowadays toward the formation of $p$ type $\mathrm{ZnO}$. This is due to the fact that the generation of $p$ type material is one of the last major obstacles hindering the development of $\mathrm{ZnO}$ based electronic and optoelectronic devices. ${ }^{1,2}$ The group $\mathrm{V}$ elements: N, P, As, and $\mathrm{Sb}$, are potential acceptors when substituting for $\mathrm{O}$ in the $\mathrm{ZnO}$ lattice. Indeed, there have been several recent reports claiming successful $p$ type doping of $\mathrm{ZnO}$ with $\mathrm{N}^{3-6} \mathrm{P}^{7,8}$ and As. ${ }^{9-11}$ In all these cases, the doping was obtained by means of a nonlocalized thin-film deposition process. For device application it would, however, be highly desirable to perform site-selective doping, by ion implantation, for example., ${ }^{2,12}$

$p$ type doping of $\mathrm{ZnO}$ is complicated by the fact that the most stable point defects in $\mathrm{ZnO}$ are donors and they dominate the transport properties of this material, ${ }^{13,14}$ hence, most bulk and thin film $\mathrm{ZnO}$ is $n$ type. Ion implantation is invariably accompanied by radiation damage, thus when ion implantation is performed in $\mathrm{ZnO}$, residual defects may dominate the electrical transport properties of the implanted layers, that will tend to exhibit $n$ type characteristics, or very poor $p$ type as the potential acceptors will be heavily compensated.

The annealing of implantation-induced lattice disorder, as well as ion implantation doping of $\mathrm{ZnO}$, has been the subject of previous studies. Of particular relevance to this work are the following results. Ion channeling experiments revealed that it is almost impossible to render $\mathrm{ZnO}$ amorphous even by liquid-nitrogen temperature implantation, and using very large doses. ${ }^{15}$ It was speculated that the sample annealed during warmup, a conjecture that is consistent with more recent electron irradiation studies, which showed that defect annihilation processes are strong at temperatures as low as $-143{ }^{\circ} \mathrm{C}(130 \mathrm{~K}) .{ }^{16} \mathrm{~A}$ combination of positron annihilation, Raman, and Hall effect measurements, ${ }^{17}$ on phosphorus-implanted single crystals of $\mathrm{ZnO}$, suggested that implantations generated vacancy-type defects which coa-

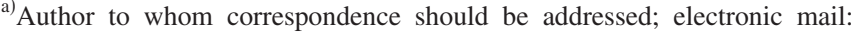
braunstein@physics.ucf.edu
}

lesced, after annealing at $\sim 700{ }^{\circ} \mathrm{C}$, to form large vacancy clusters. These clusters required very high heat treatment temperatures $\left(\geqslant 1100{ }^{\circ} \mathrm{C}\right)$ to anneal out. However, the $\mathrm{P}^{+}$-implanted layers remained $n$ type after annealing. Both of these results imply high mobility of defects at room temperature. In particular, interstitials appear to be able to migrate away from the implantation region, thus leaving behind a vacancy-rich zone that leads to the formation of the vacancy clusters observed by positron annihilation. Concomitantly, the imbalance in interstitial and vacancy local concentrations precludes defect recombination and makes the complete removal of implantation-induced lattice disorder very difficult. As indicated earlier, the more stable defects tend to be donors in $\mathrm{ZnO}$, further complicating the chances to produce $p$ type material by ion implantation.

Ion implantation has been employed to induce $n$ type electrical conductivity in $\mathrm{ZnO}$ by implantation of $\mathrm{H}^{+},{ }^{18} \mathrm{Ga}^{+}$, $\mathrm{Al}^{+}$, and $\mathrm{B}^{+}$ions, ${ }^{19}$ and creation of acceptor centers has been reported upon $\mathrm{N}^{+}$(Ref. 20) and $\mathrm{As}^{+}$(Ref. 21) implantations. These results are very encouraging, and suggest that more work is necessary to elucidate and control the effect of residual defects on the electrical properties of implanted $\mathrm{ZnO}$, in order to achieve $p$ type doping by ion implantation.

In this letter, we present results of Hall effect and conductivity measurements, demonstrating successful $p$ type doping of $\mathrm{ZnO}$ by implantation of As ions. A doping approach that had been successfully applied to the doping of diamond [the so-called cold implantation rapid annealing (CIRA) method], ${ }^{22,23}$ has been employed. This implantation/ annealing scheme consists of carrying out the implantations at a temperature low enough to freeze in the interstitials created by the irradiation, and thus avoid the creation of a defect imbalance that precludes the proper annealing of the implantation-induced lattice damage. The low-temperature implantation is followed by a very rapid in situ heating of the sample, to induce short range interstitial-vacancy recombination, and substitutional lattice location of the dopants. An ex situ annealing is carried out to further anneal any residual lattice defects, and enhance the electrical activation of the dopants. 
TABLE I. Values of sheet resistance, mobility, carrier concentration, and carrier type, determined by Hall effect and conductivity measurements, performed at room temperature, for as-prepared (CIRA implant), and as-prepared and annealed samples. Values for a conventional room-temperature As implantation, as well as the unimplanted samples, are also shown for comparison. The symbol "-" indicates that the experimental determination was not possible, usually due to the high resistivity or low mobility of the particular sample.

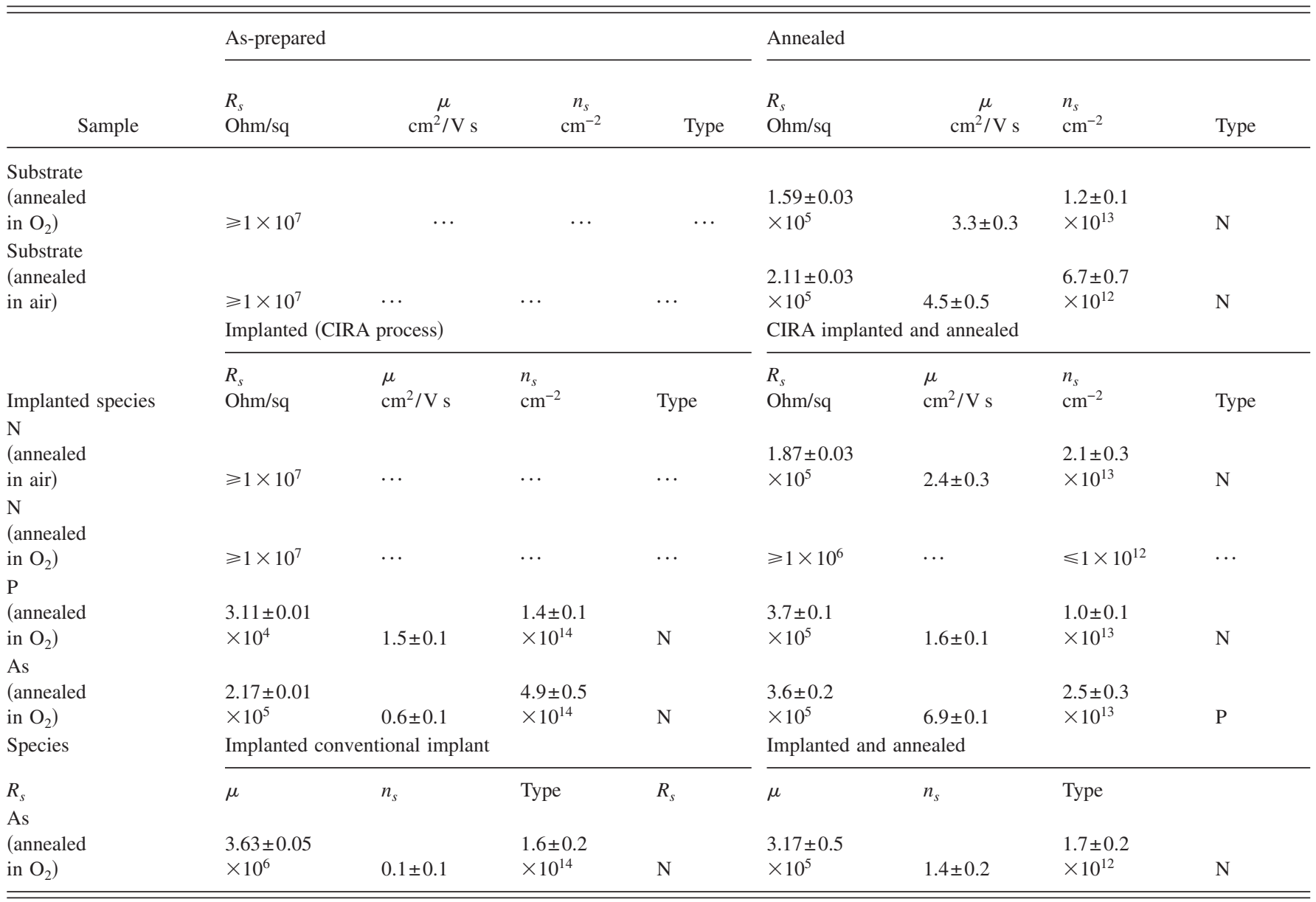

Polycrystalline thin films of $\mathrm{ZnO}$ were deposited on oxidized silicon $\left(500-1000 \mathrm{~nm}\right.$ of $\mathrm{SiO}_{2}$ on $\mathrm{Si}$ ) substrates, by radio-frequency magnetron sputtering. The depositions were performed using stoichiometric $\mathrm{ZnO}$ targets in an oxygen atmosphere, at pressures of $\sim 0.5-1.5 \times 10^{-3}$ Torr, and with the substrates at room temperature. The composition of the films was determined (and the thickness estimated) by Rutherford backscattering spectrometry (RBS) using a $2.25 \mathrm{MeV}$, $\mathrm{He}^{++}$beam, and a surface barrier detector positioned at a scattering angle of $165^{\circ}$. The program RUMP (Ref. 24) was used to fit the RBS spectra. This analysis revealed that the films were stoichiometric to within the experimental error (Zn:50 $\pm 2 \%, O: 50 \pm 2 \%$ ), with thickness of about $200 \mathrm{~nm}$ (using the density of bulk $\mathrm{ZnO}: \rho=5.6 \mathrm{~g} / \mathrm{cm}^{3}$ ). Implantation energies (calculated with SRIM 2000) ${ }^{25}$ were chosen such that the projected ranges of the implants were $\leqslant 100 \mathrm{~nm}$, i.e., well within the $\mathrm{ZnO}$ layer. Implantations were performed with the samples held at liquid-nitrogen temperature, followed by an in situ rapid heating to $500-560{ }^{\circ} \mathrm{C}$, using the CIRA approach. ${ }^{22,23}$ Subsequent thermal annealing, at $900{ }^{\circ} \mathrm{C}$, for $45 \mathrm{~min}$, was performed in a quartz tube furnace, in flowing oxygen, or in air. The potential acceptor ions, $\mathrm{N}^{+}$, $\mathrm{P}^{+}$, and $\mathrm{As}^{+}$, were implanted using the following conditions (ion, energy, dose): $\mathrm{N}^{+}, 40-50 \mathrm{keV}, 1 \times 10^{15} \mathrm{~cm}^{-2}, \mathrm{P}^{+}$, $130 \mathrm{keV}, 5 \times 10^{14} \mathrm{~cm}^{-2}, \mathrm{As}^{+}, 150 \mathrm{keV}, 5 \times 10^{14} \mathrm{~cm}^{-2}$. Resistivity, mobility, and carrier concentration, and type, were evaluated by Hall effect and conductivity measurements, at room temperature in van der Pauw four-point probe configuration. AuPd contacts were deposited near the corners of the samples by sputtering at room temperature. No further heating of the contacts was performed. Thin gold wires were attached to the contacts using In as a solder material. This procedure resulted in ohmic contacts for all samples. Only the highly resistive as-prepared samples, showed small deviations from linear behavior in current-voltage curves used to characterize the contacts.

Table I shows the results of the room-temperature Hall effect and conductivity measurements for as-implanted, and as-implanted and annealed samples. Values for the asprepared, and as-prepared and annealed $\mathrm{ZnO} / \mathrm{SiO}_{2} / \mathrm{Si}$ implantation substrates, are also presented for comparison. Figure 1 presents in graphical form the sheet carrier concentration of the samples before and after annealing in an oxygen atmosphere. The as-prepared substrate was highly resistive $\left(R_{s} \geqslant 1 \times 10^{7} \Omega\right.$ /square), and the Hall effect was too weak to allow for the determination of the carrier concentration. Upon annealing, either in oxygen or air ambient, the carrier concentration increased somewhat and became measurable (within the capabilities of our instrumentation), being $n$ type with a value of $\sim 10^{13} \mathrm{~cm}^{-2}$.

As a control, a conventional room-temperature implantation of $\mathrm{As}^{+}\left(100 \mathrm{keV}, 1 \times 10^{15} \mathrm{~cm}^{-2}\right)$ was performed. This has resulted in an $n$ type carrier concentration of $1.6 \pm 0.2$ $\times 10^{14} \mathrm{~cm}^{-2}$. After annealing in oxygen atmosphere, at 


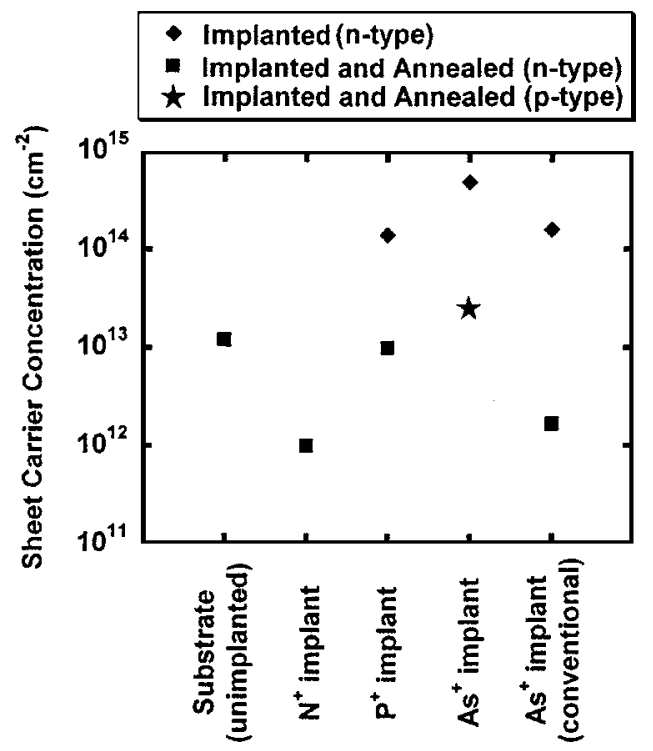

FIG. 1. Sheet carrier concentration of $\mathrm{ZnO}$ thin films measured after implantation (except for the sample labeled as unimplanted), and after implantation and annealing in oxygen atmosphere $\left(900{ }^{\circ} \mathrm{C}\right.$ for $\left.45 \mathrm{~min}\right)$. The implantations were performed using the CIRA approach except for the one labeled as conventional. Error bars are represented by the marker size.

$900{ }^{\circ} \mathrm{C}$, the sample had a rather low carrier concentration of $1.7 \pm 0.2 \times 10^{12} \mathrm{~cm}^{-2}$, still exhibiting $n$ type. However, the sample implanted with $\mathrm{As}^{+}$, using the CIRA procedure, while still being $n$ type with carrier concentration of $4.9 \pm 0.5$ $\times 10^{14} \mathrm{~cm}^{-2}$ after implantation, turned $p$ type upon annealing in oxygen atmosphere, at $900{ }^{\circ} \mathrm{C}$, with a carrier concentration slightly larger than $10^{13} \mathrm{~cm}^{-2}$. The conductivity and carrier concentration of the (unimplanted) zinc oxide thin films used in this work, increased upon heat treatment. As could be expected, the carriers generated by the heat treatment appear to be mostly donors since the films turned $n$ type. ${ }^{26}$ The sample implanted with $\mathrm{N}^{+}$, and annealed in oxygen, showed very high resistivity, and may have been highly compensated due to the presence of both acceptors produced by $\mathrm{N}$ doping, and donors produced by the heating of the substrate. The sample implanted with $\mathrm{P}^{+}$was also $n$ type. The mobility of all the implanted and annealed samples was in the single digits, as was the mobility of the annealed (unimplanted) $\mathrm{ZnO}$ substrates. Further studies are in progress to investigate these results and to try to optimize these implantation/ annealing schemes to also yield $p$ type conductivity. The sample implanted with As using the CIRA approach, exhibited a very clear Hall voltage, with polarity corresponding to $p$ type doping. However, the carrier concentration was much smaller than the implanted dose, again pointing at the presence of both types of carriers in a highly compensated sample. Interestingly, it has recently been proposed that the doping of $\mathrm{ZnO}$ with As is not due to the substitution of the larger radius As for oxygen, but rather to the formation of a complex consisting of As in the $\mathrm{Zn}$ site and two $\mathrm{Zn}$ vacancies $\left(A s_{Z n}-2 V_{Z n}\right){ }^{27}$ The present results may support this proposal.
The successful $p$ type doping of $\mathrm{ZnO}$ using the CIRA method presented here, suggests that the CIRA approach is indeed effective in preventing diffusion of interstitials during implantation, and inducing short-range interstitial-vacancy recombination during the in situ rapid anneal at $500-560{ }^{\circ} \mathrm{C}$, thus facilitating further defect annealing during the subsequent ex situ heat treatment at $900{ }^{\circ} \mathrm{C}$, for $45 \mathrm{~min}$, in oxygen. These findings may pave the way for the selective area $p$ type doping of zinc oxide, and the development of novel devices based on this material. Furthermore our findings show that CIRA implantation doping is effective not only in diamond, but it is also applicable to achieve doping in compound semiconductors.

The work performed at the University of Central Florida was supported by the National Science Foundation through Grant No. DMR 0406502.

${ }^{1}$ D. C. Look and B. Claflin, Phys. Status Solidi B 241, 624 (2004).

${ }^{2}$ S. J. Pearton, D. P. Norton, K. Ip, Y. W. Heo, and T. Steiner, J. Vac. Sci. Technol. B 22, 931 (2004).

${ }^{3}$ D. C. Look, D. C. Reynolds, C. W. Litton, R. L. Jones, D. B. Eason, and G. Cantwell, Appl. Phys. Lett. 81, 1830 (2002).

${ }^{4}$ J. F. Rommeluere, L. Svob, F. Jommard, J. Mimila-Arroyo, A. Lusson, V. Sallet, and Y. Marfaing, Appl. Phys. Lett. 83, 287 (2003).

${ }^{5}$ A. V. Singh, R. M. Mehra, A. Wakahara, and A. Yoshida, J. Appl. Phys. 93, 396 (2003).

${ }^{6}$ J. Lu, Y. Zhang, Z. Ye, L. Wang, B. Zhao, and J. Huang, Mater. Lett. 57, 3311 (2003).

${ }^{7}$ K. K. Kim, H. S. Kim, D. K. Hwang, J. H. Lim, and S. J. Park, Appl. Phys. Lett. 83, 63 (2003).

${ }^{8}$ Y. W. Heo, Y. W. Kwon, Y. Li, S. J. Pearton, and D. P. Norton, Appl. Phys. Lett. 84, 3474 (2004).

${ }^{9}$ Y. R. Ryu, T. S. Lee, and H. W. White, Appl. Phys. Lett. 83, 87 (2003).

${ }^{10}$ D. C. Look, G. M. Renlund, R. H. Burgener II, and J. R. Sizelove, Appl. Phys. Lett. 85, 5269 (2004)

${ }^{11}$ V. Vaithianathan, B. T. Lee, and S. S. Kim, Appl. Phys. Lett. 86, 62101 (2005).

${ }^{12}$ E. Rimini, Ion Implantation: Basics to Device Fabrication (Kluwer Academic, Norwell, MA, 1995).

${ }^{13}$ G. F. Neumark, Mater. Lett. 30, 131 (1997).

${ }^{14}$ S. B. Zhang, S. H. Wei, and A. Zunger, Phys. Rev. B 63, 075205 (2001).

${ }^{15}$ C. W. White, C. J. McHargue, P. S. Sklad, L. A. Boatner, and G. C. Farlow, Mater. Sci. Rep. 4, 111 (1989).

${ }^{16}$ C. Coskun, D. C. Look, G. C. Farlow, and J. R. Sizelove, Semicond. Sci. Technol. 19, 752 (2004).

${ }^{17}$ Z. Q. Chen, A. Kawasuso, Y. Xu, H. Naramoto, X. L. Yuan, T. Sekiguchi, R. Suzuki, and T. Ohdaira, J. Appl. Phys. 97, 13528 (2005).

${ }^{18}$ S. Kohiki, M. Nishitani, T. Wada, and T. Hirao, Appl. Phys. Lett. 64, 2876 (1994).

${ }^{19}$ S. Kohiki, M. Nishitani, and T. Wada, J. Appl. Phys. 75, 2069 (1994).

${ }^{20}$ C. C. Lin, S. Y. Chen, S. Y. Cheng, and H. Y. Lee, Appl. Phys. Lett. 84, 5040 (2004).

${ }^{21}$ T. S. Jeong, M. S. Han, and C. J. Youn, J. Appl. Phys. 96, 175 (2004).

${ }^{22}$ J. F. Prins, Phys. Rev. B 44, 2470 (1991).

${ }^{23}$ F. Fontaine, C. Uzan-Saguy, B. Philosoph, and R. Kalish, Appl. Phys. Lett. 68, 2264 (1996).

${ }^{24}$ L. R. Doolittle, Nucl. Instrum. Methods Phys. Res. B 15, 227 (1986).

${ }^{25}$ J. P. Biersack and J. F. Ziegler, SRIM 2000 〈available from www.srim.org〉

${ }^{26}$ O. Hamad, G. Braunstein, H. Patil, and N. Dhere, Thin Solid Films 489, 303 (2004).

${ }^{27}$ S. Limpijumnong, S. B. Zhang, S. H. Wei, and C. H. Park, Phys. Rev. Lett. 92, 155504 (2004). 